\title{
Console Gaming Across Generations: Exploring Intergenerational Interactions in Collocated Console Gaming
}

\author{
Amy Voida \& Saul Greenberg \\ Department of Computer Science, University of Calgary \\ 2500 University Dr. NW, Calgary, Alberta T2N 1N4, Canada \\ \{avoida, saul.greenberg\}@ucalgary.ca
}

In this paper, we examine the intergenerational gaming practices of four generations of console gamers, from ages 3 to 83 and, in particular, the roles that gamers of different generations take on when playing together in groups. Our data highlight the extent to which existing gaming technologies support interactions within collocated intergenerational groups and our analysis reveals a more generationally flexible suite of roles in these computer-mediated interactions than have been documented by previous studies of more traditional collocated, intergenerational interactions. Finally, we offer implications for game designers who wish to make console games more accessible to intergenerational groups.

Intergenerational gaming, console games, video games, Wii, Playstation

\section{Introduction}

Since the 1920s, opportunities for interactions among individuals of different generations have decreased dramatically [17]. There are a number of reasons for this decline including a residential revolution in which older generations stopped living with their younger family members; a movement toward mass schooling, which promoted graded interactions based on age and fostered the development of age-specific subcultures; and the rise of pension-supported retirement.

The decline in opportunities for intergenerational interaction is a significant concern $[2,19]$. From a developmental perspective, interactions with individuals of different generations are critical to human well-being. Younger individuals 
need to be able to explore the diverse relationships between themselves and others; interactions with their elders provide important opportunities for youth to expand the diversity of people with whom they interact. Additionally, older adults can be valuable role models for younger individuals, "recognizing [their] accomplishments, providing many opportunities for success, and modeling cooperation, non-violence, and other pro-social behaviors" [2]. Older individuals need opportunities to develop intimacy and to nurture others-giving of themselves, their knowledge and experiences [13]. Interactions with younger individuals can provide these kinds of opportunities for intimacy and legacy building.

Social isolation within any generation, young or old, is a significant problem [2, 19]. Increasingly, however, researchers in human-computer interaction are exploring ways that technology can help to reduce social isolation, providing opportunities for increased computer-mediated intergenerational interactions. Because of the increasingly geographically dispersed nature of many families, much attention has been paid to designing technologies that support distributed intergenerational interactions. Some of this work has focused on supporting the critical and pragmatic need for maintaining an awareness of the everyday activities of elders who remain in their own homes as they age (e.g., the Digital Family Portrait [11], the Internet Tea Kettle ${ }^{1}$, etc...). A second vein of research has explored technologies that can foster important social and playful connections among distributed family members (e.g., Age Invaders [9], The Collage [21], Curball [8], Distributed Hide and Seek [22], and Peek-A-Drawer [16]). A third line of research has emerged from an underlying acknowledgement that important social interactions may not always come from family members; these researchers have explored the participation of elders in intergenerational online communities such as SeniorNet [10] and YouTube [6].

There has been relatively little research, however, in human-computer interaction exploring technologies that support interactions within collocated intergenerational groups. While we absolutely agree that fostering social interactions among distributed intergenerational groups is a critical focus for

\footnotetext{
${ }^{1}$ http://www.mimamori.net/
} 
research, we also believe that technologies fostering collocated interactions warrant closer examination. Such collocated interactions could involve one's extended family, whether they live nearby or visit occasionally from out-of-town. Such interactions could also involve intergenerational activities among members of the local community without involving one's extended family at all. In this paper, we suggest that console gaming adds to the potential repertoire of collocated intergenerational activities in some compelling ways.

As part of our broader research agenda, we have explored various practices surrounding group console gaming. Among the gamers that we have studied, ranging in age from 3 to 83 , we found that console games have served as a computational meeting place, bringing together individuals with diverse ages, backgrounds, experiences, expertise, and interests [23]. This diversity has presented a number of challenges for gaming groups and required careful decision making about what gaming platforms to use, what games to play, and how to construct the social dynamics of the gaming environment. Most gamers we interviewed wanted to play console games with existing friends or family members; gaming skill or level of expertise was not the deciding factor when assembling gaming groups. As such, gamers adjusted to diversity as being part of the highly desired and highly valued sociability at the heart of console gaming.

The diverse sampling of gamers in our research has included many who played games in intergenerational contexts. In fact, one of our study participants expressly articulated the belief that console gaming was a "bridge" that was able to connect individuals of different generations:

P25 [Mother]: I think [our son] likes the electronicness of it.

P24 [Son]: Anything electronic I would do.

P25 [Mother]: Yeah. You just have to evolve into the new world with the youngsters.... You know, I'm not sure we would play if it wasn't for him. At least I don't think I would. We probably wouldn't have the Wii.... Do you think we'd have the Wii if it wasn't for him?

P26 [Father]: No.

P25 [Mother]: I don't think so.... It bridges the gap.

P26 [Father]: Yeah. 
P25 [Mother]: From him to us.

Further, other researchers studying the use of computer and video games in domestic settings have suggested that the generational diversity in households was exploited by various family members as a highly strategic resource for intergenerational interactions - for gaining access to social time with children, for celebrating competencies, or for controlling the organization of the gaming activity [1].

The importance of console games as a bridge among and resource for multiple generations, along with the surprising amount of diversity within gaming groups in our study, motivated us to explore intergenerational gaming practices, more specifically. In this paper, we turn to examine the intergenerational gaming practices of four generations of gamers and the roles that gamers of different generations take on when playing together in groups. Our data highlight the extent to which existing gaming technologies support interactions within collocated intergenerational groups and our analysis reveals a more generationally flexible suite of roles in these computer-mediated interactions than have been documented by previous studies of more traditional collocated, intergenerational interactions. Finally, we offer implications for game designers who wish to make console games more accessible to intergenerational groups.

\section{Method}

We conducted a mixed-methods study of collocated group console gaming, recruiting 36 participants who belonged to groups that gathered regularly to play console video games. Participants engaged in four research activities:

1. Questionnaire. Participants completed a questionnaire that asked about their previous experiences with various game genres and gaming platforms. Participants also reported basic demographic information such as sex and age.

2. Group gameplay. Participants gathered in groups of friends or family who regularly get together to play console games. These existing groups 
played the game or games that they typically play with one another for anywhere between thirty minutes and two hours (an hour and fifteen minutes, on average). We observed, kept fieldnotes, and videotaped groups as they played a variety of games on a variety of gaming platforms.

Descriptions of the gaming groups and a list of the games that were observed are reported in Table 1.

3. Gaming environment sketch. Participants sketched their ideal group gaming environment. This activity was modeled after the sketching task suggested by Sall and Grinter [14].

4. Focus group. Individuals participated in a semi-structured focus group with other members of their gaming group. The focus group protocol included questions about the participants' gaming environment sketches, their motivations for getting together to play games, and their gameplay preferences when gaming in various contexts.

Table 1 Overview of participant population.

\begin{tabular}{|c|c|c|c|c|c|c|c|c|c|c|}
\hline \multirow{3}{*}{$\begin{array}{l}\text { Gaming } \\
\text { Group }\end{array}$} & \multicolumn{8}{|c|}{ Participant Demographics } & \multirow{3}{*}{$\begin{array}{l}\text { Platform } \\
\text { Observed }\end{array}$} & \multirow{3}{*}{$\begin{array}{l}\text { Games } \\
\text { Observed }\end{array}$} \\
\hline & \multicolumn{2}{|c|}{ Youth } & \multicolumn{2}{|c|}{ Adults } & \multicolumn{2}{|c|}{ Mature Adults } & \multicolumn{2}{|c|}{ Elders } & & \\
\hline & Female & Male & Female & Male & Female & Male & Female & Male & & \\
\hline $\begin{array}{l}\text { Group A } \\
\quad \text { Siblings \& their Cousin }\end{array}$ & & $\mathrm{P} 1-\mathrm{P} 3$ & & & & & & & Wii & $\begin{array}{l}\text { Super Smash Bros Brawl } \\
\text { Mario Kart Wii }\end{array}$ \\
\hline $\begin{array}{l}\text { Group B } \\
\text { Friends }\end{array}$ & & P4-P6 & & & & & & & Wii & $\begin{array}{l}\text { Wii Sports-Tennis } \\
\text { Wii Sports-Golf }\end{array}$ \\
\hline $\begin{array}{l}\text { Group C } \\
\text { Siblings } \\
\end{array}$ & P7, P8 & & & & & & & & Gamecube & Paper Mario \\
\hline $\begin{array}{l}\text { Group D } \\
\text { Couple }\end{array}$ & & & P9 & $\mathrm{P} 10$ & & & & & Wii & Lego Star Wars \\
\hline $\begin{array}{l}\text { Group E } \\
\text { Friends }\end{array}$ & & & & $\mathrm{P} 11, \mathrm{P} 12$ & & & & & Xbox 360 & $\begin{array}{l}\text { Grand Theft Auto IV } \\
\text { Burnout Paradise } \\
\text { Halo } 3\end{array}$ \\
\hline $\begin{array}{l}\text { Group F } \\
\text { Couple }\end{array}$ & & & P13 & P14 & & & & & Xbox 360 & $\begin{array}{l}\text { Guitar Hero III } \\
\text { Rock Band }\end{array}$ \\
\hline $\begin{array}{l}\text { Group } \mathrm{G} \\
\text { Residents of a Retirement } \\
\text { Community }\end{array}$ & & & & & & & P15-P17 & & Wii & Wii Sports_-Bowling \\
\hline $\begin{array}{l}\text { Group } \mathrm{H} \\
\text { Residents of a Retirement } \\
\text { Community }\end{array}$ & & & & & & & P18-P20 & & Wii & Wii Sports_-Bowling \\
\hline $\begin{array}{l}\text { Group I } \\
\quad \text { Child \& his Parents }\end{array}$ & & $\mathrm{P} 21$ & $\mathrm{P} 22$ & $\mathrm{P} 23$ & & & & & $\begin{array}{l}\text { Wii } \\
\text { PS2 }\end{array}$ & $\begin{array}{l}\text { Boom Blox } \\
\text { American Idol (Karaoke) }\end{array}$ \\
\hline $\begin{array}{l}\text { Group J } \\
\quad \text { Child \& his Parents }\end{array}$ & & $\mathrm{P} 24$ & $\mathrm{P} 25$ & $\mathrm{P} 26$ & & & & & Wii & $\begin{array}{l}\text { Wii Sports-Tennis } \\
\text { Wii Sports-Bowling } \\
\text { Dance Dance Revolution } \\
\text { Hottest Party } \\
\text { Rock Band }\end{array}$ \\
\hline $\begin{array}{l}\text { Group K } \\
\quad \text { Couple \& } \\
\text { her Mother }\end{array}$ & & & $\mathrm{P} 27$ & P28 & P29 & & & & PS3 & Rock Band \\
\hline $\begin{array}{l}\text { Group L } \\
\text { Siblings, their Parents, } \\
\text { Uncle \& Grandparents }\end{array}$ & & P30, P31 & P32 & P33, P34 & P35 & P36 & & & Wii & $\begin{array}{l}\text { Wii Sports-Tennis } \\
\text { Wii Sports-Baseball } \\
\text { Wii Sports-Golf }\end{array}$ \\
\hline
\end{tabular}


We carried out our study in whatever setting the groups typically gathered to play games. All groups gathered in residential settings - family rooms, recreational basements, or the shared common areas of retirement communities.

In a previous publication, we characterized the strong social motivations for group console gaming [23]. In that publication, our analysis focused primarily on the focus group data. In this paper, our analysis focuses on two different slices of data that center on intergenerational gaming activities - data from the questionnaires as well as data gathered during group gameplay. First, we analyzed data from the questionnaires to understand the extent to which our participants engaged in intergenerational gaming. We employed descriptive statistical techniques to characterize these data and augmented these findings, where relevant, with additional information gleaned from the focus group data and the observations of group gameplay.

We also analyzed a subset of our observational gameplay data - the video and fieldnotes captured during the group gameplay of the four intergenerational gaming groups in our study (Groups I, J, K, and L). We transcribed the video recordings for each of these groups and then divided each transcript into discrete episodic units of intergenerational interaction. For each of these episodic units, we inductively generated descriptors for the roles taken on by the different individuals in the interaction (e.g., instructor/instructed or decision maker/supplicant). We iterated over the labeling of these roles until we arrived at descriptive language that was broad enough to encompass roles that were highly similar (e.g., the performer role was created to include both dancing and dramatic reading) and specific enough to convey the nuances that we felt were important in distinguishing among the different roles. In this analysis, we were inspired by the work of Vetere et al., who analyzed the grandparent-grandchild roles present in ten vignettes taken from their observations of grandparent-grandchild playgroups [21]. Our similar analytic process enabled us to draw some comparisons between our findings in a computer-mediated setting and their findings in more traditional play settings. 


\section{Participants}

Our participants included 36 individuals who were each part of a group that gathered regularly to play console video games. We recruited participants in the context of both inter- and intra-generational gaming groups: three groups of all youth participants, three groups of all adult participants, two groups of all elder participants, and four groups whose participants spanned multiple generations (Table 1). Based on the self-reported ages of and relationships among our participants, we clustered our participants into four generational groups. Youth participants ranged in age from 3 to 15; adult participants, from age 26 to 41; mature adult participants, from age 52 to 59; and elder participants, from age 68 to 84 . In the four intergenerational gaming groups that we studied, two groups were composed of youth and adult gamers (children and their parents), one group was composed of adult and mature adult gamers (adult children and their parents), and one group was composed of youth, adult, and mature adult gamers (children, their parents, uncle, and grandparents).

Although we specifically contacted retirement communities to recruit groups of elder participants, all other groups were recruited via snowball sampling. We did not turn away any groups; the diversity of participants in our study was a naturally occurring result of the snowball sampling. While our sampling method does allow us to examine the rich gaming practices of these 36 gamers, we do caution against over-generalizing from this small, self-selected participant population.

In all but three cases, every member of the gaming group present on the day of the observation participated in the full research design. Participants in Group F were joined briefly in their gameplay by a housemate who was just passing through the room. Participants in Groups $\mathrm{G}$ and $\mathrm{H}$ were a subset of larger gaming groups; these larger groups fluctuated in membership from 7 to 28 individuals. While a researcher observed the gameplay of the entire group, the activity coordinator at each of these retirement communities recommended individuals to participate in the remainder of the study based on their health and the schedule of other activities. 
In this paper, we refer to all of our study participants and individuals with whom they play games as "gamers." We have explicitly chosen not to perpetuate other cultural definitions of "gamer" that legitimize only certain kinds of gameplay [4].

\section{Results \& Discussion}

\section{Generations of Console Gaming Partners}

In a questionnaire, we asked our participants to indicate with what generations, relative to their own, they have played video games:

- People who are my same general age or stage in life,

- People who are a generation younger than I am,

- People who are two or more generations younger than I am,

- People who are a generation older than I am, and

- People who are two or more generations older than I am.

Participants in this study reported playing games with an average of 2.1 different generations of gamers. Thirty-one percent of the participants in our study reported playing with only one other generation of gamer-typically peers in their own generation. Sixty-nine percent of the gamers in our study played with gaming partners of a generation different from their own. While we do not have data to indicate the amount of time participants spent playing console games with various generations of gamers, these data suggest that individuals of all generations adopt gaming partners across multiple generations and, as such, intergenerational console gaming practices warrant closer examination by the research community.

If we look at the generations of console gaming partners broken down by each of the four generations of participants, we begin to see different patterns for different generations of gamers (Table 2).

Table 2 Generations of console gaming partners reported by each participant

\begin{tabular}{|c|c|c|c|c|}
\hline \multirow{2}{*}{} & \multicolumn{3}{|c|}{ Generations of Console Gaming Partners } \\
\cline { 2 - 5 } & Youth & Adults & $\begin{array}{c}\text { Mature } \\
\text { Adults }\end{array}$ & Elders \\
\hline \hline Youth Participants & & & & \\
\hline P1 & & & & \\
\hline P4 & & & & \\
\hline P7 & & & & \\
\hline P8 & & & & \\
P5 & & & & \\
\hline
\end{tabular}




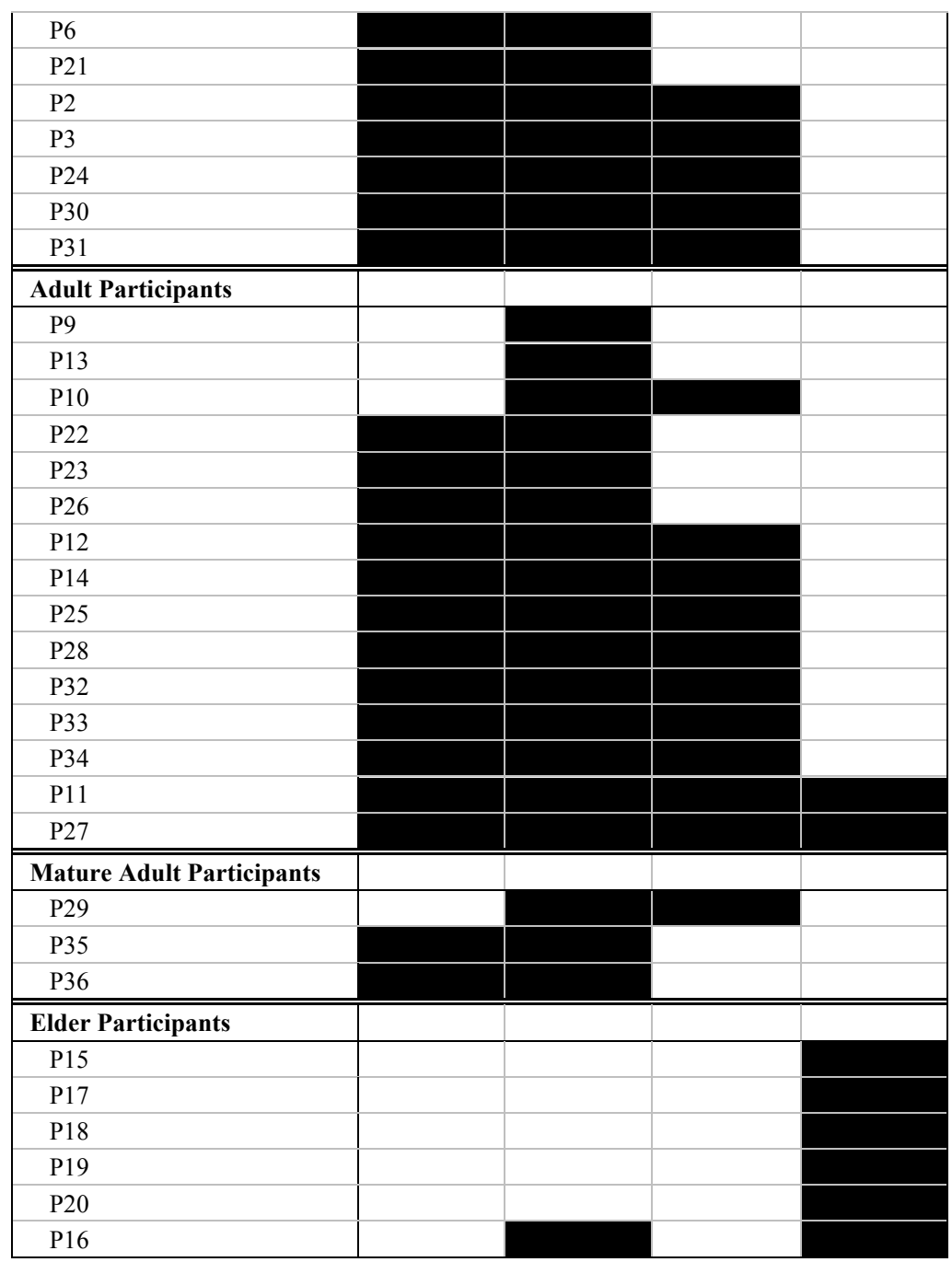

Youth participants reported, on average, having 2.1 different generations of gaming partners. As one might expect, youth participants most frequently reported having others in their peer group as gaming partners. More surprising, perhaps, is the extent to which youth gamers reported gaming with adult and mature adult partners: $75 \%$ of youth participants reported gaming with adults and $42 \%$ of youth participants reported playing with mature adult partners of their grandparents' generation.

Adult participants reported, on average, having 2.6 different generations of gaming partners. Of all participants, the adults reported the widest range of generational gaming partners, spanning from youth to elders. Two adult participants reported having gaming partners from four different generations. All adult participants played with other adult gamers; eighty percent of adult participants played with youth. The focus group data revealed that while nearly half of the adult participants in the study did not have children of their own, most 
of them had still played with youth gamers - either the children of their friends or extended family members (e.g., nieces and nephews). Sixty-seven percent of adult participants reported playing games with mature adults of their parents' generation; thirteen percent, with elders of their grandparents' generation.

We had fewer participants in our study in the mature adult generation than in any other generation, so any inferences we might make from this data set should be taken up with more caution. Nonetheless, the mature adult participants in our study were the only generation of participants who more frequently reported playing games with individuals in generations other than their own. All mature adult participants reported playing games with adult partners (their adult children). In addition, all three of these participants also reported playing games either with youth or mature adults. The variation in this data may have to do with the life stage of their adult children. The mature adult who reported playing games with her adult children and her mature adult peers (e.g., her husband and her sister) but not with youth did not have grandchildren. The two mature adults who reported playing games with youth but not with their mature adult peers did have grandchildren. While these two mature adults were married and owned the game console used in the study, they did not report ever playing games together. They used their game console when their extended family visited for regular Sunday night dinners, at which time the mature adults took turns playing with their adult children and their grandchildren.

All but one elder participant reported playing games with just one generation of gaming partners. The elder participants in our study were all residents of retirement communities and all had learned to play console games as part of that community's weekly or bi-weekly activity schedule. These elder participants, then, played games with other elders in their community. During the focus group, one elder gamer reported that when she last visited her extended family, she had been invited to play games with her adult grandson and had been pleased to surprise him by already knowing how to play Wii Sports: Bowling. No other elder participants reported playing games with anyone else in any other context.

In every instance in which a participant reported playing games with individuals two generations older than him- or her-self, that participant also reported playing 
games with individuals one generation older. In all but one instance in which a participant reported playing games with individuals two generations younger than him- or her-self, that participant also reported playing games with individuals one generation younger. While much of the intergenerational studies literature focuses on interactions among individuals two generations apart (e.g., grandparents and grandchildren), our data suggest that the intermediary generations of parents and adult children are a particularly key population in understanding practices surrounding intergenerational gaming.

\section{Generational Roles in Gameplay}

Other researchers have observed the playful activities of grandparent-grandchild pairs in intergenerational preschool playgroups [21,22]. Their analysis revealed a number of roles that grandparents and grandchildren played in their interactions. Grandparents were observed to play roles such as instructor, carer (caregiver), entertainer, comforter, and organizer, while grandchildren were observed to play roles such as apprentice, cared-for, audience, comforted, and follower.

In contrast, in a case study of the intergenerational interactions between one elder YouTube community member and the larger YouTube community, Harley and Fitzpatrick noted that the elder, in this context, took on the role of a reciprocal learner and that members of the YouTube community, primarily individuals in younger generations, took on the role of instructor [6]. Similarly, in a broader study of the formal and informal mechanisms by which people learn to use computers, Selwyn found that his respondents frequently relied on extended family members to mentor them in their learning and that, for his older respondents, the role of mentor was often taken on by their grandchildren [15].

In our study, we observed the gameplay of four intergenerational gaming groups including children and their parents (Groups I \& J); adult children and their mother (Group K); and an extended family including children, their parents, uncle, and grandparents (Group L). Our inductive analysis of the roles played by the three different generations of gamers present in these four groups (youth, adults, and mature adults) revealed both a broader repertoire of roles than has 
been documented in previous research as well as a more generationally flexible suite of roles.

In the following sections, we explore the five most common pairs of roles present across gaming groups in our data:

- Decision Maker/Negotiator,

- Configurer/Bystander,

- Instructor/Instructed,

- Discouraged Gamer/Encourager and Strategizer, and

- Performer/Audience.

\section{Decision Maker/Negotiator}

In intergenerational gameplay, there were numerous instances in which decisions about gameplay needed to be made. Gamers in different generations acted as decision makers and negotiators for different types of decisions. We observed a hierarchy of decisions that varied in their degree of impact on the gaming experience:

- Decisions about when gaming activities would begin and end,

- Decisions about who would get a turn to play,

- Decisions about what game would be played,

- Decisions about what character or role would be played by whom, and

- Decisions about specific actions undertaken within the game.

Without exception, every decision about when gaming would begin or end and every decision about who would get a turn to play were made by adults and/or mature adults.
P33 [Father]:
Okay, whose turn?
P32 [Mother]
Grandma and I were going to play next.
P30 [Son]:
No, me and Grandma!
P35 [Grandmother]: No, Mommy and Grandma.

In these instances, youth gamers employed a variety of negotiating strategiesranging from silent acquiescence when a parent definitively announced that the console needed to be turned off to declaring that they would like a turn playing 
with a particular relative to whining in an attempt to be granted more playing time.

Youth primarily took on the role of decision makers for other types of decisions including what games would be played, what role would be played by whom, and what actions would be undertaken within the game. In a number of cases when youth gamers were told to give others a chance to play, they maintained involvement in the gaming activity by leading subsequent decision-making at lower levels of the hierarchy. Directly following the exchange reported above, in which the mother and grandmother decided to play together, a youth participant stayed involved by taking on the role of decision maker regarding what game his mother and grandmother would play:

P32 [Mother]: What do you want to play, Grandma?

P31 [Son]: Baseball. Baseball....

(Pointing to his Grandmother)

Okay, you're going to be batting first.

(Pointing to his Mother)

And you're going to be pitching.

Although there were a few instances in which adults or mature adults took on the role of decision maker with respect to what game would be played and what role would be played by whom, the general pattern of interaction suggested that adults took on the more impactful decision-making activities but stepped aside to give younger generations opportunities to make some of the other decisions.

P24 [Son]: What next?

P26 [Father]: I want to play the guitar. You sing.

P25 [Mother]: You sing. You can pick the song.

P24 [Son]: Okay.

On occasion, the decision-making opportunities offered to youth gamers seemed to be somewhat concessionary, but we observed no instances in which youth gamers complained about the kinds of decisions they were invited to make. 


\section{Configurer/Bystander}

In configurer/bystander interactions, configurers set up the gaming environment by switching among game consoles, hooking up new input devices, or selecting character profiles while the other gamers, the bystanders, stood by and waited. Although most of the configuration tasks were technical in nature, some tasks were not. For example, the youth in Group L asked the adults and mature adults in their gaming group to untangle the cords connecting their Wiimotes to the Nunchuks and to switch the foam accessories on their Wiimotes from golf clubs to baseball bats.

All generations - youth, adults, and mature adults - took on the role of configurer in our data, although youth and mature adult gamers solicited the most help with configuration activities. The underlying tenor of these interactions did vary depending on the age of the configurer in the gaming group. When adults or mature adults took on the role of configurer, they typically took on the role graciously, as if acting as a host or hostess for the gaming group. In the one group in which the youth gamer took on the role of configurer, the tenor of the interactions was often imbued with less graciousness or patience:

P24 [Son]: (Selects character profiles for himself and his father) Dad!

P26 [Father]: What?

(Raises both hands in the air)

P24 [Son]: Don't press anything. I'll do it for you.

Configuration activities seemed to be some of the most difficult tasks associated with gameplay and the role of configurer was frequently taken on by the owner of the game console or by the more expert gamers in the group, regardless of the age of those individuals.

For some games, the gaming configuration activities were distributed among the input devices of various gamers. In these instances, some of the adult and mature adult gamers in our study began to transition from being bystanders to recipients of instruction as more expert gamers gave them information about how to take on the configuration tasks for their own character. 


\section{Instructor/Instructed}

Instructor/instructed interactions centered around information exchange related to the mechanics of the game: how to configure the game, what different features of the game do, what actions were expected of players at different points in the game, and what the anticipated outcomes of various actions would be. Both youth and adult gamers took on the role of the instructor in the intergenerational gaming groups; in our data, all three generations took on the role of the instructed.

P26 [Father]: Do I do these, too?

P24 [Son]: No! Don't do the stars. They take away points from you.

P26 [Father]: Really?

P24 [Son]: Yeah, that's why you are in danger.

P25 [Mother]: I thought you got extra points.

P26 [Father]: I thought so, too. That's why I was stepping on them.

P24 [Son]: They say 'watch out for stars.'

Most instances of instructor/instructed interactions were initiated by the instructed, who asked explicit questions of other group members. Most instances of these interactions also involved more than two individuals. In the previous excerpt, for example, while one individual initiated the exchange by asking the question, multiple gamers ended up taking on the role of instructed. In the following excerpt, the adult daughter and adult son-in-law shared the role of instructor while the mother took on the role of instructed.

P28 [Adult Son-in-Law]: Guitar should be in overdrive.

P27 [Adult Daughter]: If you tip it, it overdrives it... Not yet!

P29 [Mother]: $\quad$ Oh...

P27 [Adult Daughter]: Save it! Save it! Okay. You're done. But... when your music comes back, tip it, so you can get your overdrive up right away.

P28 [Adult Son-in-Law]: As soon as you get your notes, 'cuz right now it will just waste it.

Most of the instructor/instructed interactions we observed were carried out through verbal explanations as opposed to physical demonstrations. This may have been the case because these interactions largely took place during the course of gameplay and most of the people who took on the role of instructor in those 
contexts were actively playing, themselves. In one such occasion, a youth gamer was not actively playing and was able to instruct by pointing to salient pieces of information on the screen so that the instructed gamers - his parents-would know where to look.

\section{Discouraged Gamer/Encourager and Strategizer}

Some gamers routinely demonstrated or articulated that they were discouraged with their game performance. Most frequently, these gamers were youth or mature adults. Sometimes, these gamers appeared dismayed; sometimes, they were explicitly self-deprecating; at other times, they made utterances expressing frustration. In response to these discouraged gamers, another gamer, typically an adult or mature adult gamer, took on the role of an encourager and strategizer. Often, these interactions occurred during the pauses in gameplay when the scores for the previous round were displayed.

P29 [Mother]: Ninety-two? What the heck?

P27 [Adult Daughter]: Hey, ninety-two is good...

The more frustrated the gamer appeared, the more likely it seemed that the encouragement would be couched as a strategic suggestion presented in an encouraging tone of voice:

P21 [Son]: Ah, come on! That should have toppled it.... Oh no! It's not falling! It's not falling! It's not...

P22 [Mother]: You gotta slow down...

We observed the most encouragement in gaming groups in which adults were the relative gaming experts. In gaming groups in which youth were the gaming experts, we observed few instances of participants serving as encouragers and strategizers.

\section{Performer/Audience}

The role pair of performer/audience appeared repeatedly throughout our data. While the genre of performance may have varied - from celebratory dance to reenactment of a particularly successful sports play to dramatic reading or play-by- 
play announcing - the performative nature of the interaction remained constant. In nearly all cases, the role of performer in our data was taken on by the younger of the generations of gamers (whether youth or adult) and the role of the audience member was taken on by the older generation or generations of gamers (whether adult, mature adult, or both). In rare cases, the performative act seemed to exhibit a veneer of bragging and received no visible response from other group members (in which case, the lack of a visible response may have been a very intentional response by a disapproving audience). In most cases, the performances elicited visible or audible responses, for example:

P21 [Son]: I still win, 'cuz I got the 50!

(Dancing from foot to foot, waving his arms in the air)

P22 [Mother]: Is that your happy dance?

(Laughing)

P21 [Son]: (Laughing)

Yeah!

Dramatic reading was one genre of performance that transcended generation, enacted by both youth and adults. As the game presented instructions or conveyed narrative material textually on the screen, one gamer frequently read that text out loud to the rest of the gaming group:

P27 [Adult Daughter]: (Reading)

You've won a PR firm...

P29 [Mother]: Cool!

P27 [Adult Daughter]: (Reading the material presented on the screen, but adjusting the point-of-view from second- to firstperson)

We have $\$ 600$ to start. We'll be recognized by the hall of fame committee, but we need more fans.

P29 [Mother]: $\quad$ Ah...

Some adults particularly valued the role of reading in gameplay. The parents in Group I, for example, attributed their son's initial motivation for and eventual ability to read to his experiences playing games that required reading: "For me, I don't mind [my son] playing it because he's actually learning something from it... because it did force him to have to learn how to read" (P22). 
Youth and adult gamers both enacted performances as play-by-play announcers, chronicling players' activities as the game unfolded (e.g., calling "Foul Ball" in Wii Sports: Baseball or "Ace" in Wii Sports: Tennis). Sometimes the announcers were simultaneously playing the game, themselves, and at other times, being an announcer enabled them to participate more actively in the gameplay while not currently participating as a player.

The sound design of some games already included a play-by-play announcer and gamers frequently mimicked the digital voice of the game's announcer when calling the game on their own. Play-by-play announcers also frequently repeated the specific word choice of the game's built-in announcer, which often included predictable commentary on the gameplay (e.g., "Nice spare" in Wii Sports:

Bowling). The interaction between the commentary from the game, itself, and the commentary of the group's play-by-play announcer sometimes became a subject of amusement and elicited comments by other players:

Game Audio: Nice spare!

P24 [Son]: (Mimicking the game audio)

Nice spare!

P25 [Mother]: Thank you. Thank you for noticing.

The public display of scores at the end of each round sometimes presented interpretive challenges for gamers. If someone read the scores out loud, there were a number of plausible purposes for doing so - to provide a summative playby-play announcement or a commentary on the improvement or worsening of someone's scores. When an adult played the role of play-by-play announcer, it was more likely that the reading of scores was coupled with encouraging remarks or said in a celebratory tone. When youth took on the role of play-by-play announcer, they more frequently provided information without commentary. Because play-by-play information could be bound up with commentary in a variety of ways, there were instances in which the intention of the announcer seemed to have been ambiguous. In one case, the youth play-by-play announcer wanted to be certain that his calling of scores was not misconstrued as being too demeaning:

P24 [Son]: (Referring to their final Wii Sports: Bowling scores) 
Ooo... I only went down five. Dad, you went down sixty and Mom went down twenty-three.

P26 [Father]: Sixty!?

P24 [Son]: I don't know; it just said that.

Previous research has emphasized the performative nature of group gaming (e.g., $[5,14])$ and has argued that in collaborative computing, one should design more intentionally for audience members - the spectator experience [12]. The role pair of performer/audience was pervasive in our data, supporting the findings of much previous research in the area. In contrast to the specific findings of Vetere et al. [21], however, the role of performer in our data was most commonly taken up by the younger generations of gaming groups. This may be a function of the computer-mediated nature of the interaction. In grandparent-grandchild playgroups, the grandparents may have taken on the role of entertainer as part of an effort to construct a shared activity. In our data, the presence of the game may have served as that shared activity, providing entertainment for the youth gamers and creating a stage for them to perform within the constraints of the gaming activity.

\section{Designing Gaming Experiences for Intergenerational Interactions}

Our data suggest that the game design of some existing console games already supports the activities of intergenerational gaming groups. Our analysis highlights several attributes of gaming experiences that make them more accessible to intergenerational groups. Here we discuss a number of these design recommendations in more detail.

\section{Designing to Support a Breadth of Generational Involvement in Gameplay}

In our study, we observed a number of interactions in which it was apparent that older generations of gamers gave gaming priority (i.e., more opportunities to play) to gamers in younger generations. In one instance, in fact, two married mature adults did not report playing with each other; they took turns playing with their 
adult children and grandchildren, instead. To encourage a larger breadth (i.e., more generational permutations) of intergenerational gameplay, one might design games that support a larger number of players. In this way, the grandchildren get to play, a parent or two can play, and there are still characters left over for a grandparent or two to play, as well.

Limitations on the number of gamers playing at any given time may also have to do with the physical constraints of the space in which gaming takes place. Many of the games we observed groups play in intergenerational contexts required large amounts of space - either necessitating space to accommodate physical movement (e.g., Wii Sports: Tennis) or space to accommodate large physical input devices (e.g., the floor mats in Dance Dance Revolution or the drum set in Rock Band). Designing for a greater number of gamers and a larger breadth of generational involvement may also necessitate further innovation in input devices and interaction techniques that take up less space so that more players can physically fit in the domestic spaces typically used for gaming.

In our previous work, we noted that traditional input devices that had too many buttons were generally rejected by our participants as having too steep of a learning curve and demanding too much "button mashing" [23]. While traditional, button-based input devices certainly necessitate less space than the more recent physical and motion-based input devices, our recommendation to explore input devices that require a smaller spatial footprint should not be interpreted as an argument for returning to traditional, button-based controllers. Instead, we believe a new class of input devices that can be used in more space-constrained ways would be valuable.

\section{Designing to Include Intermediary Generations}

Data from the questionnaire suggested that nearly all gamers who played with gaming partners two generations older or younger than themselves also had gaming partners one generation older or younger than themselves. These intermediary generations, then - the parents or adult children — may be key both to predicting and to fostering intergenerational gaming that spans two or more generations. 
Designing to include intermediary generations may mean designing games that children (youth or adult) would enjoy playing with their parents and vice versa. Once practices of intergenerational gameplay across these two generations become commonplace, it becomes a much smaller generational stretch to include grandparents in gaming experiences, as well.

Designing to include intermediary generations may also mean designing for three or more generations of gamers to play together. In this case, designing for a larger number of gamers would become increasingly important. Beyond designing for a larger number of gamers, we observed that intermediary generations served a particularly important role in intergenerational gaming, being expert enough gamers to keep gameplay going and mature enough models of pro-social behaviors to keep people interested in playing together. This pair of characteristics seemed to be critical for engendering positive and healthy gaming experiences. When an individual was an expert gamer but not yet mature enough to model pro-social behaviors, the tenor of gameplay was less encouraging and sometimes more condescending. When an individual was able to model pro-social behaviors but was a novice gamer, they tended to be more passive participants in the social interactions surrounding the gaming activity. Individuals in the intermediary generations seemed most able to help individuals of both younger and older generations - modeling pro-social behaviors for individuals of younger generations while providing positive gaming instruction for individuals of older generations. Designing for intermediary generations, then, may also mean designing to support parents and adult children in their important niche as both role model and more expert gamer.

\section{Designing to Support Transitions Between Roles}

The computer-mediated intergenerational context for interaction seems to be a particularly fruitful site for supporting the flexible uptake of roles among individuals. Consistent with previous research in the area (e.g., $[6,15])$, our research found that interactions around computational technologies inverted some of the traditional roles taken on in intergenerational interactions (see [21]). The range of ages of individuals participating in intergenerational interactions can be 
quite large. With that age range comes a diversity of developmental abilities and degrees of social maturity. We uncovered instances in our data in which gamers from younger generations were able to take on more active leadership roles in interactions. We also identified instances in which the way a role was carried out by youth, in particular, was different in tenor from the way in which that same role was carried out by adults and mature adults. Intergenerational console gaming contexts, then, can provide an opportunity for individuals in older generations to mentor individuals in younger generations, to help them transition into these new roles and carry them out in more socially mature ways (e.g., with more graciousness and patience).

The data from this study highlight one critical transition, in particular, and give focus to the complexity of configuring games in group settings. We observed instances in which gamers were passive bystanders, waiting for someone who was more expert to set up the game and their characters as well as instances in which gamers began to take on the role of the instructed and did some of the work to configure their own characters. The prevalence of these pairs of roles and the relationship between them suggests that designing for this particular transition could be of particular importance in empowering novice users, particularly youth and mature adults. That these two generations solicited the most assistance with configuration tasks should be of interest to those who wish to design gaming technologies for grandchild-grandparent interactions, in particular. Gamers in the youth and mature adult generations will need to be empowered to take over configuration activities from the intermediary adult generation.

When one input device was the sole vehicle for configuring a gaming experience, there was little opportunity for others to learn about and take on some of their own configuration activities. One adult gamer found the hand gestures in Dance Dance Revolution to be too challenging and the youth configurer was able to assist in this transition, making his configuration activities more visible by verbally articulating each of the steps involved in turning the hand gestures off. As he moved through the menu, he read each prompt out loud as he selected it: "Options. Markers. Off" (P24). 
Game design that would make the configuration activities of one individual more visible to the group - taking advantage of the large, shared display or providing audio feedback so the configurer could more publicly model configuration skills — would be of value. This design recommendation resonates with recommendations made in the public and situated displays literature, as well [7].

When configuration was required to be distributed over multiple input devices and configurer/bystander roles were adopted, there were a number of very awkward interactions in which the configurer struggled to press buttons on devices that were either underfoot of bystanders (e.g., on the dance mats in Dance Dance Revolution) or that bystanders were wearing (e.g., on the guitars in Rock Band). If designers wish to better support the role of configurer, enabling gamers to play before they have learned how to configure their own games, then supporting configuration from one input device, at least as an option, would be of value, as well.

Designing for the transitional space between configurer/bystander and instructor/instructed may necessitate that configuration activities be allowed from a variety of input devices, so that gamers can watch visible accounts of the interaction carried out by configurers on a single input device and then begin to take on their own configuration activities across distributed input devices with the support of an instructor. In the design of intergenerational gaming experiences, the game configuration process should be approached with particular care.

\section{Conclusion}

In this paper, we have presented results from a study of the collocated multigenerational use of group console games, exploring, more specifically, the scope and nature of computer-mediated intergenerational interactions.

Our data suggest that the console game design of several existing games is already amenable to interaction within collocated intergenerational groups. Our participants reported playing with an average of two generations of gamers; some participants reported playing with up to four different generations of gamers. Our observations suggest that intergenerational interactions surrounding console 
gaming can provide some of the developmental benefits crucial to individual wellbeing: gamers in younger generations were exposed to gamers in older generations who served as models of pro-social behaviors, and gamers in older generations had opportunities to share their knowledge and experiences with gamers in younger generations. Further, in this computer-mediated context, we observed that gamers in different generations took on roles more flexibly than had been previously observed in more traditional play settings. Gamers in younger generations took on more leadership roles in gameplay and, under the watchful eye of the older generations, had opportunities to practice being more gracious experts, more patient teachers, and more thoughtful hosts and hostesses.

Beyond the benefits that group console gaming can provide across generations, this leisure technology may also help provide an entrée into computer and media literacy for a broader demographic. Research has found that peer-to-peer mentoring and informal social contexts, particularly those in the home environment, were key elements for many, especially elders, in learning to use computers [15]. In fact, leisure pursuits, such as games, were highlighted as a key example of the purposes for which individuals initially learn to use computers and have been found to be a viable platform for informal learning [18]. Intergenerational group console gaming, then, may provide a path toward more universal access of media and technology.

Our study of intergenerational console gaming suggests that the intersection of collocated intergenerational interactions and computer-supported cooperative play may be a promising focus for researchers who wish to design new technologies in support of intergenerational interactions and for proponents of community-based intergenerational programming. Our research offers motivation for exploring the design space for collocated intergenerational console gaming and suggests a number of affordances and limitations of current console game design that can be considered when designing collocated intergenerational gaming experiences.

\section{Acknowledgments}

We would like to thank our participants for sharing their time and gaming experiences with us. This research was supported in part by the 
NSERC/iCORE/Smart Technologies Chair in Interactive Technologies and by NSERC's NECTAR Strategic Networks Grants Program.

\section{References}

1. Aarsand, P.A. (2007). Computer and video games in family life: The digital divide as a resource in intergenerational interactions. Childhood, 14(2), 235-256.

2. Crites, M.S. (1989). Child development and intergenerational programming. In S. Newman \& S.W. Brummel (Eds.), Intergenerational programs: Imperatives, strategies, impacts, trends (pp. 33-43). New York, NY: Haworth Press.

3. Davis, H., Vetere, F., Francis, P., Gibbs, M. \& Howard, S. (2008). "I wish we could get together': Exploring intergenerational play across a distance via a 'magic box.' Journal of intergenerational relationships, 6(2), 191-210.

4. Dovey, J. \& Kennedy, H.W. (2006). Game cultures: Computer games as new media. New York, NY: Open University Press.

5. Ducheneaut, N., Yee, N., Nickell, E. \& Moore, R.J. (2006). “Alone together?” Exploring the social dynamics of massively multiplayer online games. In Proceedings of the SIGCHI Conference on Human Factors in Computing Systems. New York, NY: ACM Press, pp. 407416.

6. Harley, D. \& Fitzpatrick, G. (2009). YouTube and intergenerational communication: The case of Geriatric1927. Universal access in the information society, 8, 5-20.

7. Huang, E.M., Mynatt, E.D., Russell, D.M. \& Sue, A.E. (2006). Secrets to success and fatal flaws: The design of large-display groupware. IEEE Computer Graphics and Applications, 26(1), 37-45.

8. Kern, D., Stringer, M., Fitzpatrick, G. \& Schmidt, A. (2006). Curball—A prototype tangible game for inter-generational play. In Proceedings of the Workshop on Enabling Technologies: Infrastructure for Collaborative Enterprises. Los Alamitos, CA: IEEE Press, pp. 412-418.

9. Khoo, E.T., Lee, S.P., Cheok, A.D., Kodagoda, S., Zhou, Y. \& Toh, G.S. (2006). Age invaders: Social and physical inter-generational family entertainment. In Extended Abstracts of the ACM Conference on Human Factors in Computing Systems. New York: ACM Press, pp. 243-246.

10. Mynatt, E.D., Adler, A., Ito, M., Linde, C. \& O’Day, V.L. (1999). The network communities of SeniorNet. In Proceedings of the European Conference on Computer Supported Cooperative Work. Dordrecht, The Netherlands: Kluwer Academic Publishers, pp. 219-238.

11. Mynatt, E.D., Rowan, J., Craighill, S. \& Jacobs, A. (2001). Digital family portraits: Providing peace of mind for extended family members. In Proceedings of the ACM Conference on Human Factors in Computing Systems. New York: ACM Press, pp. 333-340.

12. Reeves, S., Benford, S., O'Malley, C., Fraser, M. (2005). Designing the spectator experience. In Proceedings of the SIGCHI Conference on Human Factors in Computing Systems. New York, NY: ACM Press, pp. 741-750. 
13. ReVille, S. (1989). Young adulthood to old age: Looking at intergenerational possibilities from a human development perspective. In S. Newman \& S.W. Brummel (Eds.), Intergenerational programs: Imperatives, strategies, impacts, trends (pp. 45-53). New York, NY: Haworth Press.

14. Sall, A. \& Grinter, R.E. (2007). Let's get physical! In, out, and around the gaming circle of physical gaming at home. Computer Supported Cooperative Work, 16(1-2), 199-229.

15. Selwyn, N. (2005). The social processes of learning to use computers. Social Science Computer Review, 23(1), 122-135.

16. Siio, I., Rowan, J., \& Mynatt. E. (2002). Peek-a-Drawer: Communication by furniture. In Extended Abstracts of the ACM Conference on Human Factors in Computing Systems. New York: ACM Press, pp. 582-583.

17. Stearns, P.N. (1989). Historical trends in intergenerational contacts. In S. Newman \& S.W. Brummel (Eds.), Intergenerational programs: Imperatives, strategies, impacts, trends (pp. 21-32). New York, NY: Haworth Press.

18. Stevens, R., Satwicz, T. \& McCarthy, L. (2008). In-game, in-room, in-world: Reconnecting video gameplay to the rest of kids' lives. In K. Salen (Ed.), The ecology of games: Connecting youth, games, and learning (pp. 41-66). Cambridge, MA: MIT Press.

19. Thompson, M.G. \& Heller, K. (1990). Facets of support related to well-being: Quantitative social isolation and perceived family support in a sample of elderly women. Psychology and Aging, 5(4), 535-544.

20. Ventura-Merkel, C., Liederman, D.S. \& Ossofsky, J. (1989). Exemplary intergenerational programs. In S. Newman \& S.W. Brummel (Eds.), Intergenerational programs: Imperatives, strategies, impacts, trends (pp. 173-180). New York, NY: Haworth Press.

21. Vetere, F., Davis, H., Gibbs, M. \& Howard, S. (2009). The magic box and collage: Responding to the challenge of distributed intergenerational play. International Journal of Human-Computer Studies, 67(2), 165-178.

22. Vetere, F., Nolan, M. \& Ramaan, R.A. (2006). Distributed hide and seek. In Proceedings of the Australia Conference on Computer-Human Interaction: Design: Activities, Artefacts and Environments. New York: ACM Press, pp. 325-328.

23. Voida, A. \& Greenberg, S. (2009). Wii all play: The console game as a computational meeting place. In Proceedings of the ACM SIGCHI Conference on Human Factors in Computing Systems. New York: ACM Press, pp. 1559-1568. 